\title{
INFLUENCE OF MASK LEAK ON APPLIED VOLUMES AND PRESSURES DURING SIMULATED RESUSCITATION OF NEONATES
}

\author{
J.C. Hartung, M. Kelm, H. Fischer, G. Schmalisch, C. Roehr \\ Neonatology, Charité Universitätsmedizin Berlin, Berlin, Germany
}

Introduction: Self-inflating (SI) bags and T-piece resuscitators are used for mask ventilation of neonates. Leaks between face and mask occur frequently. Little is known about the effects of mask leak on applied pressure and volume. We investigated these effects in an in-vitro study.

Method: A lung model (compliance $0.7 \mathrm{ml} / \mathrm{kPa}$ ) was ventilated with a mechanically operated SI-bag (Baby Resuscitator $^{\mathbb{B}}$ plus PEEP valve, Ambu, Denmark) and a manually operated T-piece resuscitator (Neopuff ${ }^{\mathbb{B}}$, Fisher\&Paykel, New Zealand $\left(\mathrm{PIP}=20 \mathrm{cmH}_{2} \mathrm{O}, \mathrm{PEEP}=5 \mathrm{cmH}_{2} \mathrm{O}\right.$, Flow $=81 / \mathrm{min}$, respiratory rate $(\mathrm{RR})=40,60$, $80 / \mathrm{min}$ ). To simulate mask leaks 4 open silicon tubes of increasing lengths [leak 1-4] were attached between the manual ventilation device and lung model. Two respiratory monitors $\left(\mathrm{COSMO}^{+}\right.$, Novametrix, USA) detected applied pressures and volumes $(\mathrm{Vt})$; measurements were repeated 5 times.

Results: Simulated leaks at a RR of 60/min were 22\% [1], 46\% [2], 69\% [3] and 87\% [4]. With the SI-bag mean (SD) PIP fell from 20(0.0) to $16.0(0.0) \mathrm{cmH}_{2} \mathrm{O}$, PEEP from 4.8(0.4) to $0.2(0.4) \mathrm{cmH}_{2} \mathrm{O}(\mathrm{p}<0.001)$. The pressure difference (PIP-PEEP; $\Delta \mathrm{p}$ ) increased and Vt increased from 9.1(0.6) to 11.2(0.8) $\mathrm{cmH}_{2} \mathrm{O}(\mathrm{p}<$ 0.001). Using the T-piece PIP fell from $20(0.0)$ to $18.6(0.5) \mathrm{cmH}_{2} \mathrm{O}$. PEEP, $\Delta \mathrm{p}$ and Vt were stable.

Increasing RR from 40 to 80/min lead to a significant decrease in leak with both devices and increase of PIP and PEEP with the bag. With the T-piece pressures were constant. Vt did not change significantly.

Conclusion: Mask leak has a significant impact on applied pressures and Vt. The T-piece resuscitator keeps pressures and volumes constant irrespective of leaks. 